\title{
Variação mensal do rendimento de óleo Essencial de Citronela
}

\author{
Gabriely Pinto Pereira ${ }^{1}$, Andressa Emanoela do Prado ${ }^{1}$, \\ Ruy Inacio Neiva de Carvalho ${ }^{1}$
}

${ }^{1}$ Pontifícia Universidade Católica do Paraná, Escola de Ciências da Vida, Agronomia, Rua Imaculada Conceição, 1155, Bairro Prado Velho, CEP: 80215-901Curitiba -PR, Brasil. Fone: 55413271 1534. E-mail: gabyp.pereira@hotmail.com; andressae.prado@hotmail.com; ruy.carvalho@pucpr.br

ISSN 2448-0479

Resumo - O objetivo da pesquisa foi estudar a variação mensal do rendimento de óleo essencial em folhas de citronela (Cymbopogon flexuosus) no período de um ano. $\mathrm{O}$ cultivo de citronela iniciou-se no município de São José dos Pinhais, Paraná, em clima subtropical úmido. As coletas de folhas foram realizadas de maio de 2008 a abril de 2009, no início da tarde. Foram também coletadas amostras mensais de solo e acompanhadas as variaçóes climáticas em todo período avaliado. A extração de óleo essencial foi realizada por arraste de vapor d'água utilizando-se o aparelho de Clevenger. Os maiores rendimentos de óleo essencial de folhas de citronela foram de 3,73 e 3,83\%, obtidos nos meses de janeiro e abril, respectivamente. As correlaçôes entre a produçáo de óleo essencial e a umidade da folha colhida e do solo foram de $-0,22$ e $-0,24$, respectivamente. Os maiores rendimentos foram obtidos em temperaturas mínimas no ambiente entre 15,0 e 19,1 ${ }^{\circ} \mathrm{C}$ no dia da coleta. Quando as temperaturas mínimas ficaram abaixo de $10{ }^{\circ} \mathrm{C}$, os rendimentos em óleo foram os mais baixos. Quando a temperatura máxima no mês anterior à coleta foi de $26^{\circ} \mathrm{C}$ o rendimento em óleo foi maior. Radiaçóes acima de $145 \mathrm{~W} \mathrm{~m}^{-2}$ foram favoráveis à produçáo de óleo essencial, desde que não associadas a temperaturas máximas acima de $26,5^{\circ} \mathrm{C}$. As condições climáticas distintas ao longo do ano influenciaram significativamente o rendimento de óleo essencial em folhas de citronela em clima subtropical.

Palavras-chave - Cymbopogon flexuosus. Temperatura. radiação solar.
Abstract - This work aimed to study the monthly variation of essential oil production in citronella leaves (Cymbopogon flexuosus) within one year. The plants of citronella were cultivated in São José dos Pinhais, Paraná, in humid subtropical climate. The monthly leaf samples were obtained from May 2008 to April 2009, in the early afternoon. Soil samples were also collected monthly and the climatic variations throughout the period were monitored. The essential oil was obtained by hydrodistillation in a Clevenger apparatus. The highest essential oil production of citronella leaves were 3.73 and 3.83\%, obtained in January and April, respectively. The correlations between the essential oil produced and the moisture of harvested leaf and soil were -0.22 and -0.24 , respectively. The highest productions were obtained in minimum temperatures in the environment between 15.0 and $19.1{ }^{\circ} \mathrm{C}$ on the harvest day. When the minimum temperatures were below $10{ }^{\circ} \mathrm{C}$, the production of oil was the lowest. When the maximum temperature in the month before the harvest was $26^{\circ} \mathrm{C}$ the production of oil was the highest. Radiation above $145 \mathrm{~W} \mathrm{~m}^{-2}$ were favorable to the production of essential oil, provided that not associated with maximum temperatures above $26.5^{\circ} \mathrm{C}$. The different climatic conditions throughout the year influenced the essential oil production in citronella leaves in subtropical climate. Keywords - Cymbopogon flexuosus. Temperature. Solar radiation.

Recebido em: 06 de maio de 2016.

Aprovado em: 07 de agosto de 2016. 


\section{INTRODUÇÃO}

Os óleos essenciais são produtos naturais provenientes do metabolismo secundário de diversas espécies conhecidas como plantas bioativas (PINTO et al., 2002). Estes óleos, por possuírem aroma agradável e intenso, são também chamados essências e são obtidos de partes de plantas através de destilação por arraste com vapor d'água (SIMÓES; SPITZER, 2003).

Dentre as plantas aromáticas amplamente utilizadas, encontra-se o capim citronela (Cymbopogon sp.), cujo óleo essencial tem sua aplicação agrícola como bactericida (AMORIM et al., 2011), fungicida (FIALHO; PAPA; FERREIRA, 2015), inseticida (COLPO; JAHNKE; FULLER, 2014), acaricida (ANDREOTTI et al., 2011) ou nematicida (MOREIRA et al., 2015).

O óleo essencial do capim citronela apresenta vários compostos químicos, com maior concentração dos compostos citronelal, \-citronelol, geraniol e elemol (VELOSO et al., 2012). O citronelol, além de possuir ação inseticida e repelente contra insetos, anti-microbiana local e acaricida, também é muito utilizado para a fabricação de cosméticos e perfumes (CHAGAS et al., 2002). Por ser natural e não apresentar problemas de toxicidade a quem o utiliza e nem ao ecossistema, o óleo essencial de citronela vem sendo estudado no controle de Phakopsora pachyrhizi, fungo causador da ferrugem da soja (MEDICE et al., 2007) e no controle de carrapatos de bovinos (OLIVO et al., 2008).

A produção de princípios ativos nas plantas depende do controle genético e também das interaçóes genótipo e ambiente, que podem ser desencadeadas em condiçóes de excesso ou deficiência de algum fator ambiental que pode afetar a produtividade, a composição e a quantidade dos constituintes dos óleos essenciais (ANDRADE; CASALI, 1999; OLIVEIRA et al., 2000). As características de cultivo, assim como a idade da planta, parte utilizada, altura e horário de corte, espaçamento, métodos para amostragem das folhas, processos para extração e de análise de óleo, além da variabilidade genética também podem influenciar o rendimento do óleo essencial (LEAL et al., 2001).

Koshima et al. (2006) apresentaram resultados de maiores produçóes de óleo essencial em capim-limão e de seu componente citral nas colheitas de inverno e outono, períodos com precipitaçôes pluviais e temperaturas médias menores. Já em Eucalyptus citriodora, o maior rendimento de óleo essencial foi obtido em folhas colhidas no mês de fevereiro (CASTRO et al., 2008).
Segundo Costa Filho et al. (2006), o crescimento e o desenvolvimento de Ocimum gratissimum sáo influenciados pela disponibilidade hídrica e térmica, e em regime hídrico próximo a capacidade de campo do solo e somas térmicas acima de 80 graus-dia semanais, os indivíduos têm seu crescimento e produtividade acelerados, resultando em maior quantidade de matéria prima para extração de óleo. Em Polygonum punctatum, foi verificado maior teor de óleo essencial em indivíduos submetidos a estresse hídrico (LOPES et al., 2001). Porém, a composição química de óleos essenciais pode ser influenciada pela deficiência hídrica (ANDRADE; CASALI, 1999).

O rendimento de óleo essencial no capim citronela é muito variável em função das condiçôes climáticas, encontrando-se valores de $0,2 \%$ a até $4,18 \%$ em funçấo da região de cultivo (MARCO et al., 2007; ROCHA et al., 2012).

O presente trabalho foi desenvolvido com o objetivo de estudar a variaçáo mensal do rendimento de óleo essencial de folhas de citronela (Cymbopogon flexuosus) em clima subtropical no período de um ano.

\section{MATERIAIS E MÉTODOS/METODOLOGIA}

As plantas matrizes estudadas foram classificadas pelo biólogo Marlon Alves Selusniaki como Cymbopogon flexuosus (DC.) Stapf. e a excicata foi depositada no herbário HUCP do Setor de Botânica e Zoologia da Pontifícia Universidade Católica do Paraná com o registro número 20.827 .

As folhas de capim citronela e amostras de solo foram coletadas em área de produção localizada no município de São José dos Pinhais, Paraná, com altitude média de $906 \mathrm{~m}$, latitude de $25^{\circ} 32^{\prime} 00^{\prime \prime}$ Sul e longitude de $49^{\circ} 12^{\prime} 00^{\prime \prime}$ Oeste. O clima regional é classificado como subtropical úmido mesotérmico com veróes frescos e invernos com ocorrências de geadas severas e frequentes, com temperaturas médias inferiores a $18^{\circ} \mathrm{C}$ e não apresenta estação seca.

As coletas foram realizadas de maio de 2008 a abril de 2009, na segunda quinzena de cada mês entre 13:00 e 14:00 horas. Para a extração do óleo essencial, três amostras de $70 \mathrm{~g}$ de folhas frescas e íntegras, coletadas de matrizes clonadas de dois anos, foram levadas à estufa de secagem a $35^{\circ} \mathrm{C}$ por 48 horas para retirada da umidade. Após esse período, foram separadas três amostras de $20 \mathrm{~g}$ de folhas picadas em fragmentos de $1 \mathrm{~cm}$ para extração do óleo essencial por arraste de vapor d'água utilizando-se aparelho de Clevenger, por 
duas horas. O rendimento de óleo essencial foi calculado em porcentagem de massa seca de folhas.

Em cada coleta, foram também coletadas quatro amostras de $50 \mathrm{~g}$ de folhas de capim citronela para a determinação da umidade do tecido vegetal. As amostras foram levadas à estufa a $65^{\circ} \mathrm{C}$ por 48 horas. Da mesma forma, amostras de solo foram retiradas em cada data na profundidade de $0 \mathrm{a} 20 \mathrm{~cm}$ próximas à touceira da matriz. Cada amostra de solo foi separada em quatro repetiçóes de $100 \mathrm{~g}$ e levada à estufa para secagem a 105 ${ }^{\circ} \mathrm{C}$ por 48 horas para determinaçáo da umidade.

No início do experimento foram coletadas amostras de solo $(0$ a $20 \mathrm{~cm})$ para análise química e os resultados foram os seguintes: $\mathrm{pH}$ em $\mathrm{CaCl}_{2}=5,60 ; \mathrm{C}=$ $33,76 \mathrm{~g} \mathrm{dm}^{-3}$; P-Mehlich $=24,56 \mathrm{mg} \mathrm{dm}^{-3}$; K-Mehlich $=0,82 \mathrm{cmol}_{\mathrm{c}} \mathrm{dm}^{-3} ; \mathrm{Ca}=9,04 \mathrm{cmol} \mathrm{dm}_{\mathrm{c}} \mathrm{dm}^{-3} ; \mathrm{Mg}=4,75$ $\mathrm{cmol}_{\mathrm{c}} \mathrm{dm}^{-3} ; \mathrm{Al}=0,00 \mathrm{cmol}_{\mathrm{c}} \mathrm{dm}^{-3} ; \mathrm{H}+\mathrm{Al}=4,61 \mathrm{cmol}_{\mathrm{c}}$ $\mathrm{dm}^{-3} ; \mathrm{SB}=14,60 \mathrm{cmol}_{\mathrm{c}} \mathrm{dm}^{-3} ; \mathrm{T}=19,21 \mathrm{cmol}_{\mathrm{c}} \mathrm{dm}^{-3} ; \mathrm{V}$ $=76,00 \% ; \mathrm{m}=0,00 \%$. De acordo com níveis de interpretação propostos por Tomé Junior (1997), o solo apresentou alta fertilidade, sem necessidade de calagem.

O clima regional ao longo de todo o ano foi analisado por meio de dados fornecidos pelo Sistema Meteorológico do Paraná (2009) e calcularam-se as condiçôes de precipitação $(\mathrm{mm})$, temperaturas máximas, médias e mínimas $\left({ }^{\circ} \mathrm{C}\right)$, umidade relativa do ar (\%) e radiação solar ( $\left.\mathrm{W} \mathrm{m}^{-2}\right)$ em quatro situaçôes distintas: no dia da coleta; no dia anterior à coleta; na semana anterior à coleta e no período entre duas coletas. Para a primeira coleta, foram considerados os 15 dias anteriores à coleta.

O delineamento experimental adotado foi o de blocos casualizados com 12 tratamentos (coletas mensais de amostras de solo e planta) e quatro repetiçóes. Os dados foram submetidos à análise da variância e as médias dos tratamentos com diferença significativa pelo teste $\mathrm{F}$ foram submetidas ao Teste Tukey $(\mathrm{p} \leq 0,05)$. Foi realizada a análise de correlaçáo de Pearson entre o rendimento em óleo essencial e todos os fatores climáticos e os dados de umidade das folhas e do solo.

\section{RESULTADOS E DISCUSSÃO}

O rendimento médio mensal de óleo essencial de citronela foi de $2,80 \%$ e este é superior aos rendimentos encontrados em vários outros locais do Brasil, em especial de clima quente. Rocha et al. (2012), no norte de Minas Gerais, obtiveram rendimento de 0,2 a $0,3 \%$ e atribuíram o baixo rendimento à alta temperatura da região de $35^{\circ} \mathrm{C}$. A produção de óleos vo- láteis pode aumentar em temperaturas elevadas, mas perdas excessivas destes metabólitos podem ocorrer em dias muito quentes (GOBBO-NETO; LOPES, 2007). Oliveira et al. (2011), em Lavras no sul de Minas Gerais, encontraram teores médios mais elevados de $2,27 \%$ com colheita às 8 horas da manhã, em um dia com temperatura amena. No Tocantins, em clima quente, os rendimentos encontrados foram de $1,15 \%$ para Castro et al. (2007) ou de 0,79 a $0,90 \%$ para Veloso et al. (2012). Castro et al. (2010) também encontraram, em cinco épocas de colheita distintas, teores entre 0,65 e 1,10\% no Tocantins.

Os maiores rendimentos de óleo essencial de folhas de citronela foram obtidos nos meses de janeiro e abril, 3,73 e 3,83\%, respectivamente (Tabela 1). Estes valores elevados estão próximos aos relatados por Marco et al. (2007) em cultivos no Ceará em temperaturas médias de $26,8{ }^{\circ} \mathrm{C}$, que citaram teores de 3,52 a $4,18 \%$.

As correlaçōes entre a porcentagem de óleo essencial produzido e a umidade da folha colhida $(\mathrm{r}=$ $-0,22)$ e do solo $(r=-0,24)$ foram baixas, porém negativas, indicando que em condiçôes de umidade mais baixa do solo e da planta o rendimento em óleo tende a ser mais elevado. Lopes et al. (2001) encontraram maior teor de óleo essencial em plantas de Polygonum punctatum submetidas a estresse hídrico (LOPES et al., 2001).

Tabela 1 - Umidade do solo e de folhas de citronela (Cymbopogon flexuosus) e rendimento de óleo essencial no período de um ano, em São José dos Pinhais, Paraná.

\begin{tabular}{|c|c|c|c|c|c|c|}
\hline \multirow{3}{*}{$\begin{array}{c}\text { Mês } \\
\text { Mai }\end{array}$} & \multicolumn{4}{|c|}{ Umidade (\%) } & \multirow{2}{*}{\multicolumn{2}{|c|}{$\begin{array}{c}\text { Rendimento em } \\
\text { óleo essencial } \\
(\%)\end{array}$}} \\
\hline & \multicolumn{2}{|c|}{ Solo } & \multicolumn{2}{|c|}{ Folhas } & & \\
\hline & 27,2 & $\mathrm{e}$ & 66,0 & bc & 2,78 & cde \\
\hline Jun & 43,5 & abcd & 63,3 & c & 2,83 & cde \\
\hline Jul & 26,5 & e & 69,7 & $a b$ & 1,87 & f \\
\hline Ago & 44,0 & $a b c$ & 68,0 & $a b c$ & 2,33 & def \\
\hline Set & 46,8 & $\mathrm{a}$ & 72,9 & a & 2,26 & ef \\
\hline Out & 46,0 & $a b$ & 70,6 & $a b$ & 2,75 & cde \\
\hline Nov & 47,5 & $a$ & 67,8 & $a b c$ & 2,33 & def \\
\hline Dez & 40,2 & bcd & 68,6 & $a b c$ & 2,84 & cde \\
\hline Jan & 38,9 & $\mathrm{~cd}$ & 69,7 & $a b$ & 3,73 & $a b$ \\
\hline Fev & 46,3 & $a b$ & 65,5 & bc & 3,00 & $\mathrm{~cd}$ \\
\hline Mar & 37,8 & d & 68,2 & $a b c$ & 3,08 & bc \\
\hline Abr & 24,4 & $\mathrm{e}$ & 67,7 & $a b c$ & 3,83 & $\mathrm{a}$ \\
\hline $\begin{array}{l}\text { CV } \\
(\%)\end{array}$ & & & & & & 93 \\
\hline
\end{tabular}

Médias seguidas pela mesma letra nas colunas não diferem entre si pelo Teste de Tukey $(\mathrm{p} \leq 0,05)$. 
As maiores correlaçóes positivas foram obtidas entre o rendimento em óleo essencial nas folhas e as temperaturas médias e mínimas ocorridas no dia da coleta, no dia anterior, na semana anterior e no interalo entre duas coletas. As temperaturas máximas e a radiação solar incidente tiveram correlaçâo maior e positiva quando considerou-se a semana ou o mês anterior à coleta, mas não tiveram correlação elevada no dia ou no dia anterior à coleta. Apenas a precipitação e a umidade relativa do ar no dia ou nos dias anteriores à coleta não apresentaram correlação elevada com o rendimento em óleo essencial nas folhas (Tabela 2).

Analisando-se isoladamente cada dado climático em que se verificou maior correlação, percebeu-se que a temperatura mínima do ar teve maior influência no rendimento de óleo em citronela. De acordo com a Tabela 3, os maiores rendimentos foram obtidos em temperaturas mínimas no ambiente entre 15,0 e $19,1{ }^{\circ} \mathrm{C}$ no dia da coleta. Nas coletas de maio a setembro, quando as temperaturas mínimas no dia da coleta variaram entre 4,2 e $14,1{ }^{\circ} \mathrm{C}$, os rendimentos em óleo se situaram entre
1,87 e $2,83 \%$ e quando as temperaturas mínimas não foram táo baixas o rendimento foi elevado para 3,00 a $3,83 \%$.

O efeito da temperatura mínima do dia anterior à coleta foi semelhante ao da temperatura do dia da coleta. Quando ocorreram temperaturas mínimas entre 6,2 e $13,6{ }^{\circ} \mathrm{C}$ no dia anterior, o rendimento em óleo foi mais baixo, e quando as temperaturas mínimas foram um pouco mais elevadas, entre 14,7 e $18,9^{\circ} \mathrm{C}$ o conteúdo em óleo na folha foi maior. Considerando-se um efeito mais longo de baixas temperaturas, detectou-se que quando as temperaturas mínimas da semana ou do mês anterior à coleta situaram-se entre 15,4 e $16,5^{\circ} \mathrm{C}$, os rendimentos em óleo foram superiores. De modo geral, quando as temperaturas mínimas ficaram abaixo de $10{ }^{\circ} \mathrm{C}$, os rendimentos em óleo foram os mais baixos. Blank et al. (2007) cultivando citronela em Sergipe obtiveram teores mais baixos no inverno $(2,33 \%)$ que na primavera $(3,5 \%)$. Em plantas de Foeniculum vulgare, Sousa et al. (2005) encontraram tendência à diminuição no teor de óleo essencial do final do inverno para o final da primavera.

Tabela 2 - Coeficiente de correlação entre o conteúdo de óleo essencial em folhas de citronela (Cymbopogon flexuosus) e condiçóes ambientais no local de cultivo em São José dos Pinhais, Paraná.

\begin{tabular}{|l|c|c|c|c|}
\hline \multirow{2}{*}{ Condição climática } & \multicolumn{3}{|c|}{ Coeficiente de correlação com o conteúdo em óleo essencial } \\
\cline { 2 - 5 } & No dia da coleta & $\begin{array}{c}\text { No dia anterior à } \\
\text { coleta }\end{array}$ & $\begin{array}{c}\text { Na semana anterior à } \\
\text { coleta }\end{array}$ & $\begin{array}{c}\text { No intervalo entre as } \\
\text { coletas }\end{array}$ \\
\hline Precipitação $(\mathrm{mm})$ & 0,08 & 0,35 & $-0,01$ & 0,17 \\
Temperatura máxima $\left({ }^{\circ} \mathrm{C}\right)$ & 0,28 & 0,14 & 0,49 & 0,58 \\
Temperatura média $\left({ }^{\circ} \mathrm{C}\right)$ & 0,51 & 0,39 & 0,60 & 0,61 \\
Temperatura mínima $\left({ }^{\circ} \mathrm{C}\right)$ & 0,51 & 0,54 & 0,60 & 0,62 \\
Umidade relativa $(\%)$ & 0,06 & 0,23 & $-0,03$ & 0,04 \\
Radiação solar $\left(\mathrm{W} \mathrm{m}{ }^{-2}\right)$ & 0,25 & 0,08 & 0,41 & 0,62 \\
\hline
\end{tabular}

Nas condições de temperaturas médias no dia da coleta entre 19,4 e $20,1^{\circ} \mathrm{C}$ e na semana anterior entre 17,9 e $21,5^{\circ} \mathrm{C}$ os rendimentos em óleo foram superiores (Tabela 4). Quando no dia da coleta ou na semana anterior as temperaturas médias ficaram abaixo de $16^{\circ} \mathrm{C}$ a produção de óleo essencial foi menor. Porém, no mês de outubro a temperatura média ficou acima de $16^{\circ} \mathrm{C}$ e o rendimento em óleo também foi baixo. Analisando-se a Tabela 5 , verificou-se que a temperatura máxima e a radiação solar neste mês foram mais baixas o que pode ter implicado na menor produção de óleo na folha. Em condiçóes de temperaturas médias entre 19,6 e $20,3^{\circ} \mathrm{C}$ na semana ou no mês anterior à coleta, as produçôes de óleo essencial foram maiores. Quando a temperatura média do período anterior à coleta não ultrapassou os $19^{\circ} \mathrm{C}$ o rendimento em óleo tendeu a ser menor. Oliveira et al. (2011), em Lavras no sul de Minas Gerais, encontraram teores médios mais elevados de 2,27\% com colheita às 8 horas da manhã, em um dia com temperatura amena. 
Tabela 3 - Condições de temperaturas mínimas ocorridas no local de cultivo de citronela (Cymbopogon flexuosus) durante o período de colheita em São José dos Pinhais, PR.

\begin{tabular}{|l|c|c|c|c|c|c|}
\hline \multirow{2}{*}{ Mês } & \multirow{2}{*}{$\begin{array}{c}\text { Rendimento } \\
\text { em óleo } \\
\text { essencial (\%) }\end{array}$} & \multicolumn{4}{|c|}{ Temperatura mínima $\left({ }^{\circ} \mathrm{C}\right)$} \\
\cline { 4 - 7 } & No dia & & $\begin{array}{c}\text { No dia } \\
\text { anterior } \\
\text { à coleta }\end{array}$ & $\begin{array}{c}\text { Na semana } \\
\text { anterior à } \\
\text { coleta }\end{array}$ & $\begin{array}{c}\text { Entre } \\
\text { as co- } \\
\text { letas }\end{array}$ \\
\hline Mai & 2,78 & cde & 10,1 & 10,9 & 10,3 & 10,1 \\
Jun & 2,83 & cde & 4,2 & 7,6 & 11,3 & 11,7 \\
Jul & 1,87 & f & 5,9 & 6,2 & 9,5 & 9,7 \\
Ago & 2,33 & def & 13,2 & 13,6 & 12,2 & 11,6 \\
Set & 2,26 & ef & 14,1 & 11,1 & 9,5 & 11,8 \\
Out & 2,75 & cde & 17,3 & 18,4 & 14,7 & 12,3 \\
Nov & 2,33 & def & 13,5 & 16,4 & 16,5 & 15,9 \\
Dez & 2,84 & cde & 15,1 & 12,7 & 15,7 & 15,1 \\
Jan & 3,73 & ab & 19,1 & 18,9 & 16,3 & 16,5 \\
Fev & 3,00 & cd & 17,4 & 16,2 & 16,8 & 18,1 \\
Mar & 3,08 & bc & 15,1 & 16,1 & 16,3 & 17,9 \\
Abr & 3,83 & a & 15,0 & 14,7 & 15,4 & 15,9 \\
\hline
\end{tabular}

Médias seguidas pela mesma letra na coluna não diferem entre si pelo Teste de Tukey $(\mathrm{p} \leq 0,05)$.

Tabela 4 - Condiçóes de temperaturas médias ocorridas no local de cultivo de citronela (Cymbopogon flexuosus) durante o período de colheita em São José dos Pinhais, PR.

\begin{tabular}{|l|c|c|c|c|c|c|}
\hline \multirow{2}{*}{ Mês } & \multirow{2}{*}{$\begin{array}{c}\text { Rendimento } \\
\text { em óleo } \\
\text { essencial (\%) }\end{array}$} & \multicolumn{4}{|c|}{ Temperatura média $\left({ }^{\circ} \mathrm{C}\right)$} \\
\cline { 4 - 7 } & \multicolumn{2}{|c|}{$\begin{array}{c}\text { No dia } \\
\text { da coleta }\end{array}$} & $\begin{array}{c}\text { No dia } \\
\text { anterior } \\
\text { à coleta }\end{array}$ & $\begin{array}{c}\text { Na semana } \\
\text { anterior à } \\
\text { coleta }\end{array}$ & $\begin{array}{c}\text { Entre } \\
\text { as co- } \\
\text { letas }\end{array}$ \\
\hline Mai & 2,78 & cde & 13,8 & 13,7 & 13,6 & 13,7 \\
Jun & 2,83 & cde & 11,8 & 12,5 & 16,4 & 16,5 \\
Jul & 1,87 & $\mathrm{f}$ & 14,3 & 14,2 & 14,9 & 14,5 \\
Ago & 2,33 & def & 14,8 & 19,1 & 14,7 & 15,9 \\
Set & 2,26 & ef & 18,2 & 13,7 & 14,9 & 17,2 \\
Out & 2,75 & cde & 22,0 & 24,1 & 18,8 & 15,7 \\
Nov & 2,33 & def & 15,9 & 18,1 & 19,0 & 18,9 \\
Dez & 2,84 & cde & 18,2 & 18,0 & 19,7 & 18,8 \\
Jan & 3,73 & ab & 20,1 & 21,5 & 19,0 & 20,3 \\
Fev & 3,00 & cd & 19,4 & 18,3 & 19,7 & 21,3 \\
Mar & 3,08 & bc & 20,4 & 19,8 & 19,7 & 21,7 \\
Abr & 3,83 & a & 19,4 & 17,9 & 19,6 & 20,0 \\
\hline
\end{tabular}

Médias seguidas pela mesma letra na coluna não diferem entre si pelo Teste de Tukey $(\mathrm{p} \leq 0,05)$

Quando a temperatura máxima no mês anterior à coleta ficou por volta de $26^{\circ} \mathrm{C}$ o rendimento em óleo foi maior. Temperaturas máximas acima de 26,5 e abaixo de $24,3{ }^{\circ} \mathrm{C}$ estiveram associadas à redução do conteúdo em óleo na folha. A radiação solar incidente abaixo de $128 \mathrm{~W} \mathrm{~m}^{-2}$ esteve associada a conteúdos mais baixos em óleo essencial. Radiações acima de $145 \mathrm{~W} \mathrm{~m}^{-2}$ foram favoráveis à produção de óleo essencial, desde que não associadas a temperaturas máximas acima de $26,5^{\circ} \mathrm{C}$ (Tabela 5). Marco et al. (2007) obtiveram os maiores rendimentos de 3,52 a $4,18 \%$ de óleo em cultivos de citronela em clima tropical no Ceará com temperaturas médias de $26,8^{\circ} \mathrm{C}$.

Tabela 5 - Condições de temperatura máxima e radiação sola ocorridas entre as coletas de folhas de citronela (Cymbopogon flexuosus) em São José dos Pinhais, PR

\begin{tabular}{|l|c|c|c|c|}
\hline Mês & \multicolumn{2}{|c|}{$\begin{array}{c}\text { Rendimento em } \\
\text { óleo essencial }\end{array}$} & $\begin{array}{c}\text { Temperatura } \\
\text { máxima média } \\
\left({ }^{\circ} \mathrm{C}\right)\end{array}$ & $\begin{array}{c}\text { Radiação } \\
\text { solar média } \\
\left.(\mathrm{W} \mathrm{m})^{-2}\right)\end{array}$ \\
\cline { 4 - 6 } & \multicolumn{2}{|c|}{$(\%)$} & \multicolumn{2}{|c|}{ No intervalo entre as coletas } \\
\hline Mai & 2,78 & cde & 18,3 & 99,4 \\
Jun & 2,83 & cde & 22,1 & 112,0 \\
Jul & 1,87 & $\mathrm{f}$ & 20,6 & 103,5 \\
Ago & 2,33 & def & 21,1 & 93,6 \\
Set & 2,26 & ef & 23,4 & 127,9 \\
Out & 2,75 & cde & 20,6 & 114,9 \\
Nov & 2,33 & def & 23,7 & 118,0 \\
Dez & 2,84 & cde & 24,3 & 176,3 \\
Jan & 3,73 & ab & 25,9 & 157,5 \\
Fev & 3,00 & cd & 26,5 & 146,3 \\
Mar & 3,08 & bc & 27,5 & 160,0 \\
Abr & 3,83 & a & 26,0 & 147,8 \\
\hline
\end{tabular}

Médias seguidas pela mesma letra na coluna não diferem entre si pelo Teste de Tukey $(\mathrm{p} \leq 0,05)$.

\section{CONCLUSÃO}

O maior rendimento de óleo essencial obtido em folhas de citronela foi obtido em janeiro e abril. As condiçôes mais associadas ao maior rendimento em óleo no momento da colheita foram a menor umidade do solo e da folha e temperaturas mínimas no ambiente entre 15,0 e $19,1^{\circ} \mathrm{C}$. Temperaturas máximas no mês anterior à coleta de $26^{\circ} \mathrm{C}$ e radiaçóes acima de $145 \mathrm{~W} \mathrm{~m}^{-2}$ foram favoráveis à produção de óleo essencial. Temperaturas abaixo de $10^{\circ} \mathrm{C}$ induziram menores rendimentos em óleo.

\section{REFERÊNCIAS}

AMORIM, E.P.R. et al. Atividade antibacteriana de óleos essenciais e extratos vegetais sobre o desenvolvimento de Ralstonia solanacearum em mudas de bananeira. Revista Brasileira de Fruticultura, Jaboticabal, v.33, n.esp.1, p.392-398, 2011.

ANDRADE, F.M.C.; CASALI, V.W.D. Plantas medicinais e aromáticas: relaçấo com $\mathrm{o}$ ambiente, colheita $\mathrm{e}$ 
metabolismo secundário. Viçosa: Universidade Federal de Viçosa, Departamento de Fitotecnia, 1999.

ANDREOTTI, R. et al. Acaricide resistance of Rhipicephalus (Boophilus) microplus in State of Mato Grosso do Sul, Brazil. Revista Brasileira de Parasitologia Veterinária, Jaboticabal, v.20, n.2, p.127-133, 2011.

BLANK, A.F. et al. Influence of season, harvest time and drying on Java citronella (Cymbopogon winterianus Jowitt) volatile oil. Revista Brasileira de Farmacognosia, João Pessoa, v.17, n.4, p.557-564, 2007.

CASTRO, H.G. et al. Crescimento, teor e composição do óleo essencial de Cymbopogon nardus (L.). Revista Brasileira de Plantas Medicinais, Botucatu, v.9, n.4, p.55-61, 2007.

CASTRO, H.G. et al. Avaliação do teor e composição do óleo essencial de Cymbopogon nardus (L.) em diferentes épocas de colheita. Revista Ciência Agronômica, Fortaleza, v.41, n.2, p.308-314, 2010.

CASTRO, N.E.A. et al. Avaliação de rendimento e dos constituintes químicos do óleo essencial de folhas de Eucalyptus citriodora Hook. colhidas em diferentes épocas do ano em municípios de Minas Gerais. Revista Brasileira de Plantas Medicinais, Botucatu, v.10, n.1, p.70-75, 2008.

CHAGAS, A.C.S. et al. Efeito acaricida de óleos essenciais e concentrados emulsionáveis de Eucalyptus spp em Boophilus microplus. Brazilian Journal of Veterinary Research and Animal Science, São Paulo, v.39, n.5, p.247-253, 2002.

COLPO, J.F.; JAHNKE, S.M.; FULLER, T. Potencial inseticida de óleos de origem vegetal sobre Grapholita molesta (Busck) (Lepidoptera: Tortricidae). Revista Brasileira de Plantas Medicinais, Botucatu, v.16, n.2, p.182188, 2014.

COSTA FILHO, L.O. et al. Influência hídrica e térmica no crescimento e desenvolvimento de Ocimum gratissimum L. Revista brasileira de Plantas Medicinais, Botucatu, v.8, n.2, p.8-13, 2006.

FIALHO, R.O.; PAPA, M.F.S.; PEREIRA, D.A.S. Efeito fungitóxico de óleos essenciais sobre Phakopsora euvitis, agente causal da ferrugem da videira. Arquivos do Instituto Biológico, Sáo Paulo, v.82, p.1-7, 2015.

GOBBO-NETO, L.; LOPES, N.P. Plantas medicinais: fatores de influência no conteúdo de metabólitos secundários. Química Nova, v.30, n.2, p.374-381, 2007.

KOSHIMA, F.A.T. et al. Produção de biomassa, rendimento de óleo essencial e de citral em capim-limão, Cymbopogon citratus (DC.) Stapf, com cobertura morta nas es- taçóes do ano. Revista Brasileira de Plantas Medicinais, Botucatu, v.8, n.4, p.112-116, 2006.

LEAL, T.C.A.B. et al. Avaliação do efeito da variação estacional e horário de colheita sobre o teor foliar de óleo essencial de capim-cidreira (Cymbopogon citratus (DC) Stapf). Revista Ceres, Viçosa, v.48, n.278, p.445-453, 2001.

LOPES, R.C. et al. Influência de três regimes hídricos na produção de óleo essencial em sete acessos de Polygonum punctatum Ell. Revista Brasileira de Plantas Medicinais, Botucatu, v.3, n.2, p.7-10, 2001.

MARCO, C.A. et al. Características do óleo essencial de capim-citronela em função de espaçamento, altura e época de corte. Horticultura Brasileira, Brasília, v.25, n.3, p.429-432, 2007.

MEDICE, R. et al. Óleos essenciais no controle da ferrugem asiática da soja Phakopsora pachyrhizi. Ciência e Agrotecnologia, Lavras, v.31, n.1, p.83-90, 2007.

MOREIRA, F.J.C. et al. Controle alternativo de nematoide das galhas (Meloidogyne incognita) raça 2, com óleos essenciais em solo. Summa Phytopathologica, Botucatu, v.41, n.3, 207-213, 2015.

OLIVEIRA, A.F.M. et al. Screening cromatográfico de Acanthaceae medicinais: Justicia pectoralis Jacq. e J. gendarussa Burm. Revista Brasileira de Plantas Medicinais, Botucatu, v.3, n.1, p.37-41, 2000.

OLIVEIRA, M.M.M. et al. Rendimento, composição química e atividade antilisterial de óleos essenciais de espécies de Cymbopogon. Revista Brasileira de Plantas Medicinais, Botucatu, v.13, n.1, p.8-16, 2011.

OLIVO, C.J. et al. Óleo de citronela no controle do carrapato de bovinos. Ciência Rural, Santa Maria, v.38, n.2, p.405-410, 2008.

PINTO, A.C. et al. Produtos naturais: atualidade, desafios e perspectivas. Química Nova, São Paulo, v.25, supl.1, p.45-61, 2002.

ROCHA, H.C.R. et al. Crescimento, produção de fitomassa e teor de óleo essencial de folhas de capim citronela (Cymbopogon nardus (L.) Rendle) em cultivo consorciado com algodoeiro colorido no semiárido mineiro. Revista Brasileira de Plantas Medicinais, Botucatu, v.14, n.esp., p.183-187, 2012.

SISTEMA METEOROLÓGICO DO PARANÁ. Instituto Tecnológico SIMEPAR. Curitiba, Maio de 2009. Arquivo eletrônico.

SIMÓES, C.M.O.; SPITZER, V. Óleos voláteis. In: SI- 
MÕES, C.M.O. et al. Farmacognosia: da planta ao medicamento. Porto Alegre: UFRGS; Florianópolis: UFSC, 2003. p. 467-495.

SOUSA, L.A. Sazonalidade dos ductos secretores e óleo essencial de Foeniculum vulgare Mill. (Apiaceae). Revista Brasileira de Farmacognosia, João Pessoa, v.15, n.2, p.155-161, 2005.

TOMÉ JUNIOR, J.B. Manual para interpretação de análise de solos. Guaíba: Agropecuária, 1997.

VELOSO, R.A. et al. Composição e fungitoxicidade do óleo essencial de capim citronela em função da adubação orgânica. Pesquisa Agropecuária Brasileira, Brasília, v.47, n.12, p.1707-1713, 2012. 